\title{
Commonplace
}

\section{Librarians' perceptions and motivations for supporting collaborative models for Open Access monographs}

Mirela Roncevic

Published on: Apr 02, 2021

DOI: $10.21428 / 6 \mathrm{ffd} 8432.00 f 389 \mathrm{c} 1$

License: Creative Commons Attribution 4.0 International License (CC-BY 4.0). 
As part of my doctoral research at the University of Zagreb-which examines the factors that contribute to the sustainability of collaborative Open Access (OA) models for scholarly books (i.e., monographs) - I recently surveyed librarians across Europe with knowledge of or dealings with OA monographs and collaborative OA business models designed to finance their publishing. The study focused exclusively on monographs (not journals) and on collaborative business models referred to as crowdfunding or cross-institutional global initiatives. Examples of such initiatives include (but are not limited to) Knowledge Unlatched, Unglue.it, and Reveal Digital.

Crowdfunding in academic libraries is a funding model for OA scholarly books that has attracted the academic community's attention for much of the last decade. According to this model, institutions worldwide join forces to 'open' scholarly books or collections of scholarly books most often referred to as 'monographs.' Some have a very narrow definition of monographs (long-form scholarly argument on a very specialized academic topic, authored by a single or a group of scholars), while others accept a broader definition (thus also calling edited collections of essays on a specific academic topic monographs). Such OA collections may be multi-disciplinary, subject-specific or tied to individual publishers. The funds collected via crowdfunding are distributed to publishers and authors to help scholars and/or institutions avoid Book Processing Charges (BPCs) and to help publishers and/or authors cover the production costs associated with publishing monographs.

While the quantitative method of the months-long research involved a thorough examination of OA book usage data for 167 institutions in 32 European countries (inside and outside the European Union) - and examined the profiles of the institutions supporting such initiatives to determine the type of institutions that appear to be more inclined to invest in such initiatives (including, e.g., the institution's world ranking, its international outlook, research output and the number of FTE students and faculty as ranked by three well-known university ranking sources) - the research was supplemented by an anonymous, multi-national survey of librarians across Europe to determine their attitudes about and perceptions of global collaborative OA models and their motivations for supporting (or not supporting) them. The survey's goal was to deepen the understanding of the factors that may contribute to the long-term sustainability of such business models beyond those examined in the quantitative part.

Librarians from university and national libraries across Europe involved with OA initiatives were invited to answer ten questions, two of which clarified their roles in 
the context of OA and their institutions' main scholarly focus. The other eight questions centered on the reasons they supported crowdfunding monographs and what they perceived as the main obstacles in their decision-making process. Participants were given four weeks to respond voluntarily (and without compensation).

Between January 25th and February 21st, 2021, 160 librarians took part in the survey, of whom 80 percent identified themselves as being directly and actively involved with OA initiatives at their institutions, while the remaining 20 percent were not directly involved but remained interested in its development. Of the librarians directly involved with OA, 46 percent were decision-makers and 33 percent participated in OA initiatives at their institution without the authority to make decisions regarding funding. The respondents' institutions' main academic focus varied: 27 percent said the primary focus of their institution was the Humanities; for 27 percent it was Social Sciences; for 22 percent it was STEM; for 18 percent it was the Arts; and for 5 percent the chosen answer was "Other," which was described as "multi-disciplinary," "all," "business," or "law."

\section{Key findings}

While the survey revealed several discoveries regarding librarians' confidence in collaborative OA models for monographs, one of the key findings was that librarians still support the basic principle of OA-despite the obstacles standing in the way-and are willing to support OA models for scholarly books via crowdfunding to help make them available worldwide. They also do not overlook the importance of local benefits (i.e., the benefits for their own communities) derived from their participation. Previous studies on OA already confirmed librarians' positive attitudes about supporting OA monograph publishing: OAPEN-UK 2014 librarian survey, for example, revealed that 80 of librarians would support OA monograph publishing merely in principle (Collins \& Milloy,_2016). The study did not focus on a particular model, but it did show librarians' commitment to OA, not only in the context of journals but also monographs.

Fifty-three percent of respondents said they supported OA initiatives because of the belief that scholarship should be accessible and open to researchers worldwide. In comparison, 16 percent also believed that scholars should not pay to publish their work; instead, their institutions should step in and use their funds to support the publishing of their scholarship. Supporting local researchers can also be seen as a position of supporting OA in principle. Interestingly, local usage of monographs did not 
have to be high in those institutions for them to justify participating. Similarly, when asked if high usage of OA books at their institution positively influenced their perceptions of participating in crowdfunding campaigns, 50 percent said that usage was relevant but not crucial. In comparison, 46 percent said that high usage should motivate institutions to support OA monographs.

The same percentage of librarians that support OA in principle-53 percent-said they did not support (or could not support) collaborative OA models owing to budget restrictions or ongoing budget cuts. Another 21 percent said they did not support such initiatives because after reviewing the lists of titles suggested to be published OA, they concluded that they would not be relevant for their communities (which, in turn, would likely result in them not being used). The issue of the relevance of disciplines brings to mind the issue of content quality and publisher reputation brought up in many papers and studies previously and which scholars have often cited as the reasons they were cautious about publishing long-form scholarship OA (e.g., Elliott,2015;

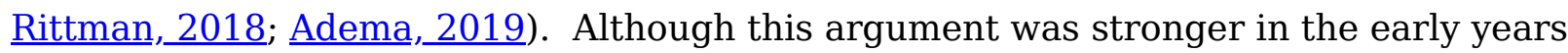
of OA monograph publishing, it appears to have subsided recently, owing in large part to the fact that established (therefore reputable) publishers have since embraced the publishing of OA monographs with more vigor and subject them to the same peer review process and editorial standards as the books published traditionally.

As mentioned above, librarians cared the books published OA covered the subjects and disciplines that matter to their institutions. Forty-nine percent said their institutions should support collaborative OA monograph initiatives if they covered the disciplines that were relevant in their communities, while the other 49 percent said while they would be more inclined to support if the subjects supported their institution's programs, but this was not the deciding factor. The remaining two percent said that information about the types of disciplines covered should not have significance. Likewise, it seems to help if the monographs funded are authored by local scholars. Fifty-one percent of librarians said they believed institutions should support OA collections featuring the work of their researchers, while 48 percent believed this factor was an important but not a crucial factor.

The first few questions of the survey revolved around studying the importance of the 'local' impact of OA monographs by focusing on the importance of usage data, author background, and disciplines covered. The results showed that a majority of librarians were committed to supporting the idea of OA and open science (as they have already shown in previous studies), even if they did not directly benefit from it on a local level. 
However, when it comes to supporting crowdfunding business models for OA monographs, they seem especially motivated when the authors' background and the disciplines/subjects covered are strongly relatable to their communities. When asked specifically about the importance of local impact as a determining factor for supporting OA monographs, only 11 percent felt it was 'extremely important' that local impact was evident (i.e., that those books were used at their institution, that authors were affiliated with their institutions/ and that the subjects covered mattered to their institution), 39 percent said it was 'relatively important.' In comparison, 45 percent felt it was 'important but not crucial.' In other words, about half of the respondents said it was either 'extremely important' or 'relatively important' to have proof of local impact, while the other half felt it was not crucial (45 percent) or not important at all (6 percent).

What are the main challenges of Open Access book publishing today?

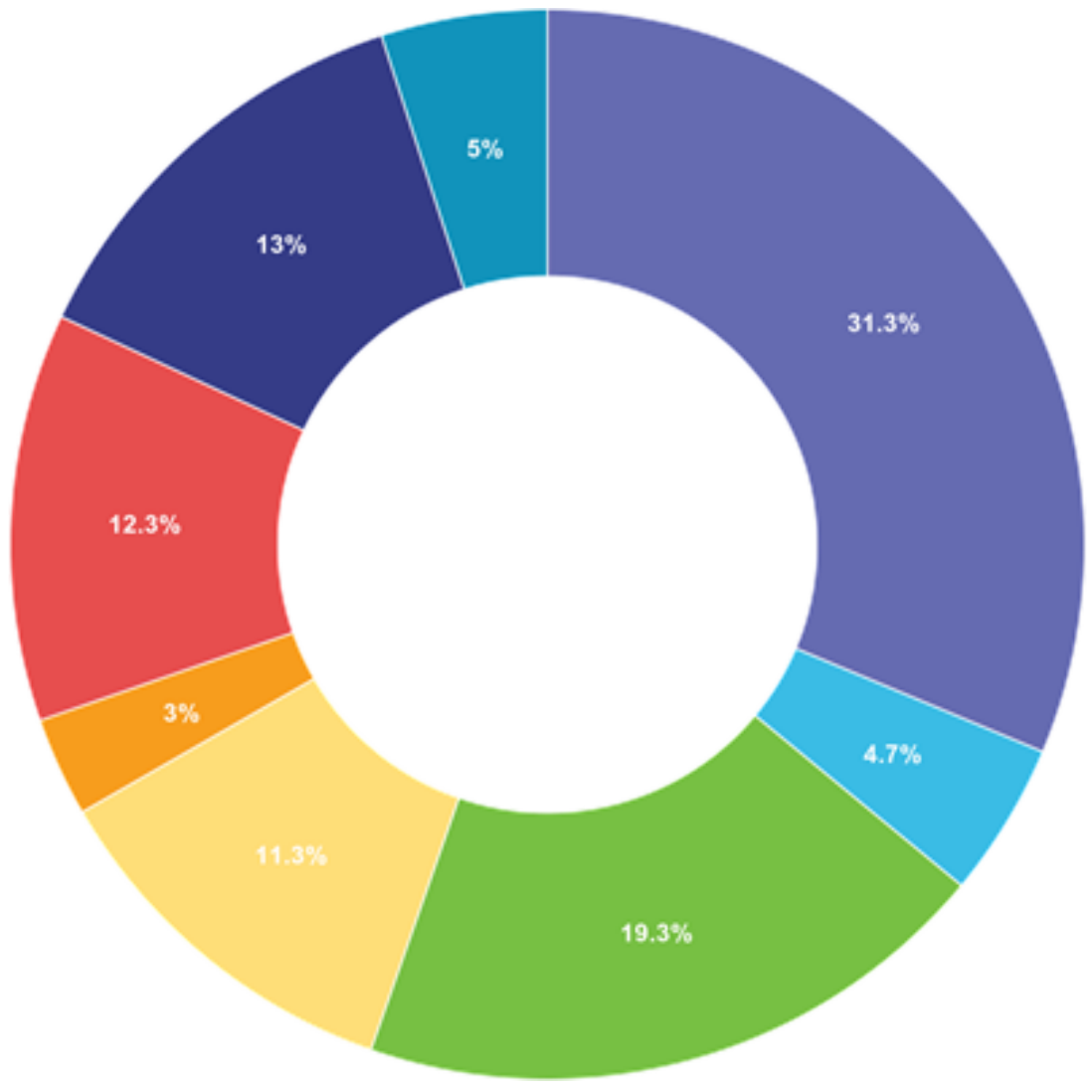




\footnotetext{
Choice

-The cost of funding Open Access books is still high.

- Content published traditionally is still of higher quality.

\section{Results from the survey question: "What are the main challenges of Open} Access book publishing today?"
}

The question of sustainability yielded similar results as the question of the local impact: 49 percent believed collaborative OA models would succeed if libraries worldwide continued to participate in large numbers, while 50 percent were undecided, as more time was needed to evaluate the model's long-term sustainability. The reasons for their indecision were revealed in the following question on the main obstacles facing OA monograph publishing today. Here, no single 'obstacle' prevailed, although the steep cost of OA monographs tops the list. Thirty-one percent of librarians said the key obstacle to supporting OA monograph publishing was the steep cost of the monographs. The other reasons included: 1) not enough established scholars participating (19 percent); 2) librarians being overwhelmed with the sheer volume of OA initiatives to keep up (12 percent); 3) supporting journals and subscription services remained a priority (13 percent); and 4) more business models needed to be tested to determine what worked best for all sides of the scholarly ecosystem (11 percent).

Aside from various collaborative models being tested, others include the well-known APC (Author Processing Charges) models (authors or their institutions pay publishing fees); freemium models (one version of the work is free, others, more substantial, are not); community models (researchers in specific disciplines join forces to make literature in their field OA worldwide through the use of their institutional funds); and 
new university press models (the establishment of new university presses that receive subsidies from their institutions that want to support in-house publishing ventures).

Each of these comprises various sub-models, attesting to the fact that the landscape of OA monograph publishing has become quite diverse and complex. The reason for the existence of so many models is quite simple: There is no such thing as 'free' OA. Publishing anything OA means that someone will have to fund it, if not the institution or a funder, then the author him or herself. As Crossick stated, "it is unlikely that one or two business models would prevail, in contrast to journals, and a variety would be

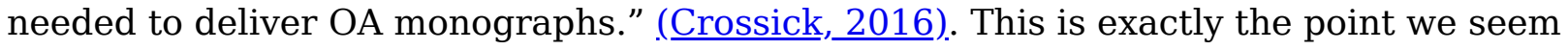
to have reached in 2021.

\section{Conclusion}

In summary, European librarians continue to have confidence in publishing scholarly books OA via crowdfunding on a global level. Their motivations are largely still rooted in the belief that scientific knowledge should be available without restrictions worldwide. They seem particularly interested in participating in such initiatives when 'local' benefits are apparent. While evidence of local usage is perceived as somewhat (rather than relatively or extremely) relevant, it does not appear to be the deciding factor. However, authors' backgrounds and disciplines covered carry significantly more weight.

In conclusion, the same obstacles to funding OA publishing cited by librarians in previous years continue to this day: more funds are needed for more collaborative OA initiatives for monographs to survive as libraries across Europe still use most of their budgets on journals and subscription services. Further, while OA content has come a long way in terms of quality and diversity since the earlay days of the OA movement, more such content must be published in the future, including more established presses and recognized scholars, and more testing is needed all around to determine the effectiveness of various OA business models as they relate to monographs and librarians' willingness to finance them. 


\section{Author Bio}

Mirela Roncevic is a doctoral candidate at the University of Zagreb, where she has studied information and communication science, with a special focus on Open Access, open science, and open virtual libraries. She is Managing Director of No Shelf Required, a well-known web site which has followed the development of e-books and digital content in libraries since 2007.

\section{Citations}

1. Collins, Ellen \& Caren Milloy (2016). “OAPEN-UK final report: A five-year study into open access monograph publishing in the humanities and social sciences." OAPENUK. Jisc. $\doteq$

2. Elliott, Michael (2015). "The Future of the Monograph in the Digital Era: A Report to the Andrew W. Mellon Foundation.” Journal of Electronic Publishing 18(4).

3. Rittman, Martyn (2018). "Sustainability in Publishing: An Open Access Publisher's View.” ELPUB 2018, Jun 2018, Toronto.

10.4000/proceedings.elpub.2018.9..

4. Adema, Janneke (2019). “Towards a Roadmap for Open Access Monographs.” Knowledge Exchange Stakeholder Workshop. $\_$

5. Crossick, Geoffrey. (2016). “Monographs and open access.” Insights 29(1): 1419. $\doteq$ 